\title{
Study of the obstetrics and perinatal outcome of in vitro fertilization pregnancies at tertiary care centre
}

\author{
Geetha D. Balsarkar, Shraddha P. Pol*
} Department of Obstetrics and Gynaecology, Seth G. S. Medical College and KEM Hospital, Mumbai, Maharashtra,
India

Received: 01 November 2020

Revised: 30 April 2021

Accepted: 01 May 2021

*Correspondence:

Dr. Shraddha P. Pol,

E-mail: shraddhapol65@gmail.com

Copyright: (C) the author(s), publisher and licensee Medip Academy. This is an open-access article distributed under the terms of the Creative Commons Attribution Non-Commercial License, which permits unrestricted non-commercial use, distribution, and reproduction in any medium, provided the original work is properly cited.

\begin{abstract}
Background: Assisted reproductive techniques (ART) has been a boon to the unfortunate. However, the outcomes aren't the same to all. The study has observed the outcomes in IVF conceived patients. The pregnant women were followed-up throughout their antenatal and post-natal (7 days) period and an appropriate meta-analysis was made. Methods: This is an Observational Prospective study. It was conducted at an IVF center of tertiary hospital. With valid written informed consents 96 patients were recruited and observed for 18 months. Data collected by Universal sampling method, analyzed and interpreted.

Results: A total $65.6 \%$ belonged above 30 years, $67.7 \%$ were primigravida and $7.3 \%$ had history of previous ectopic pregnancy. In $23.75 \%$ multifetal pregnancy was significant and $20.63 \%$ had OS tightening done. Most common reason for opting IVF was multiple failed IUI (71.6\%). More than 40\% were delivered by caesarean section. $91.1 \%$ of babies cried immediately after birth and $50.4 \%$ babies required NICU admission. $13.4 \%$ babies had neonatal death and $3.1 \%$ were IUFD. $58.30 \%$ pregnancies were singleton. Mean birth weight was $1.87 \mathrm{Kg}$ and $72.6 \%$ children were born low birth weight. Statistical significance $(\mathrm{p}<0.001)$ was found in between no. of foetuses delivered and preterm delivery. $56.3 \%$ birth were preterm birth. PIH and GDM complication is most common in multiple gestations observed in $10.7 \%$ of pregnancies.

Conclusions: Assisted Reproductive technologies has helped the infertile couples. Outcomes could be unfruitful in few, while others may have a complicated antenatal period. Preterm deliveries are more common in multiple gestation thus complementing the lower birth weights. Comorbidities significantly affected obstetric outcome.
\end{abstract}

Keywords: In vitro fertilization, Intra uterine foetal death, Assisted reproductive technologies, Preterm, Low birth weight

\section{INTRODUCTION}

Assisted reproductive technologies (ARTs) are the techniques to help a woman become pregnant, including in vitro fertilization (IVF), intracytoplasmic sperm injection (ICSI), and other similar procedure. ${ }^{1}$ In vitro fertilization means the process of achieving fertilization between the sperm and ovum in the laboratory under artificial conditions, and placement of the dividing zygote into the uterus of the mother.

There has been a widespread acceptance to IVF worldwide. It will not be an exaggeration if In vitro fertilization was called 'a Boon to Medical field' for the infertile couples. In vitro fertilization has thus been a key to having healthy babies and for a woman to enjoy a healthy motherhood. 
Prior to 1978, women without functioning fallopian tubes were largely considered to be sterile by their physicians. At least one patent fallopian tube was necessary for natural fertilization of an oocyte by sperm in vivo. In the past, many women with damaged tubes resorted to reparative surgery, or tuboplasty in hopes of reestablishing a conduit for gametes to transit. Unfortunately, often these surgeries failed. Other maternal complications like gestational diabetes, hypertensive disorders and postpartum hemorrhage. ${ }^{2}$

Lesley Brown in the late 1970's, a patient with nine years of primary infertility secondary to tubal occlusion, sought the assistance of Patrick Steptoe and Robert Edwards at the Oldham General Hospital in England. At that time, fertilization of oocytes outside the human body, a process known as in vitro fertilization (IVF), was considered entirely experimental and when attempted had only resulted in miscarriages and an unsuccessful pregnancy in the fallopian tube. Embryo transfer resulted in the first live birth from IVF was a daughter Louise Brown, who was born in the year July 1978.

Of the various treatment options available for the treatment of infertility, in vitro fertilization has been found to be the best. The use of these reproductive techniques has generated tremendous interest, concern and controversy in the recent years.

With IVF, a method of assisted reproduction, a man's sperm and the woman's egg are combined, after which fertilization occurs. The resulting embryo or embryos is/are then transferred to the woman's uterus (womb) to implant naturally. Usually, two to four embryos are placed in the woman's uterus at one time. Each attempt is called a cycle.

The term "test tube baby" has been used for children conceived with this technique. Harsha Chawda was India's first test tube baby. She herself delivered a stillto-be-named baby boy with same assisted reproduction technique 'IVF. The conventional method by which the success of any infertility therapy is judged is by the pregnancy rate after specified periods of treatment. However, what matters is being blessed by a healthy baby. In this regard consideration of the obstetric outcome of IVF pregnancies is of paramount importance. In the decade since the birth of the first child conceived as a result of IVF the IVF technique has emerged as an essential method in the treatment of infertility. Although success rates are best related to the cumulative conception rates after specified periods of treatment, the most important outcome to the patient is the probability of bringing home a normal, healthy baby. Vitrification had no clinically relevant adverse effects on obstetric and perinatal outcomes after adjusting for potential confounders. Cobo et al conducted a retrospective cohort study at a private university-affiliated IVF center to assess outcomes after oocyte vitrification on obstetric and perinatal outcomes compared with those achieved with fresh oocytes. The study concluded that oocyte vitrification does not increase adverse obstetric and perinatal outcomes in children conceived with vitrified oocytes.

Around less than $5 \%$ of infertile couples actually use IVF procedure. IVF is usually the treatment of choice in a woman with blocked, severely damaged, or no fallopian tubes. It is also used to overcome infertility caused by the medical conditions like Oligospermia in man or by endometriosis or and in Couples who simply can't conceive and have tried other infertility methods (such as intrauterine insemination) that have not worked for them can also try the IVF.

The significant advances in the field of human reproduction and the introduction of various assisted reproduction techniques to alleviate infertility have raised major concerns about the health of the offspring, for the reason that the several stages of natural fertilization are usually bypassed while early embryonic development takes place in vitro. Moreover, apart from the potential risk for genetic defects, malformations and other adverse consequences for the children born after assisted reproduction techniques, another interesting question is whether there is any association between the type of conception and the obstetric or perinatal outcome.

This study was therefore undertaken to study antenatal, intra-natal and postnatal outcomes of In vitro fertilization at tertiary care center.

\section{METHODS}

The prospective observational study conducted at Nowrosjee Wadia IVF centre attached to Seth G. S. Medical College and KEM Hospital for 18 months i.e. from February 2018 to August 2019 included 96 participants who were biochemically confirmed pregnancy conceived by in vitro fertilization technique.

\section{Inclusion criteria}

All IVF pregnancies irrespective of age groups or any other co-morbid conditions.

\section{Exclusion criteria}

All Intrauterine insemination conceptions. All normally conceived pregnancies.

\section{Study procedure}

\section{Step I: Designing of questionnaire (Annexure-1)}

A semi-structured questionnaire was designed included general information about patient, medical history, menstrual history, obstetrics history, relevant past history, USG findings, Foetal and neonatal data at birth. 


\section{Step II: Validation of questionnaire}

The semi-structured questionnaire was drafted validated with the help of field experts.

\section{Step III: Consent}

Those who are willing to participate in the study, informed consent was taken from them. The semistructured questionnaire was administered. Participants included will be studied for indications and will be followed up throughout their antenatal period for any complications as well as for obstetric and perinatal outcomes. With due consents patients conceived out of IVF shall be observed till the end of their pregnancies and 7 days after that. Depending upon the outcomes, a systematic analysis would be made graphically and numerically.

\section{Data collection}

Data will be collected by Universal sampling method, and through clinical case records like- outdoor record papers, indoor record papers, USG scans, labor ward record, NICU records.

\section{Data analysis}

Data analysis included following steps.

\section{Step I}

All responses were tabulated by using Microsoft-Excel 2013 Software. Descriptive analysis information about patient, medical history, menstrual history, obstetrics history, relevant past history, USG findings, Fetal and neonatal data at birth was done and presented in the form of tables and figures. Graphical representation was made wherever necessary.

\section{Step II}

Data was analysed by using Statistical package for social sciences (SPSS) software version 22.0. Data was summarized using proportions, percentages and contingency tables. Chi square test was used for statistical inference. Unpaired t test was used to compare means between two groups. It being an observational study, no comparison was done with normal pregnancies.

\section{RESULTS}

The study was done at tertiary maternity hospital. The results are discussed below.

\section{Figure $1(N=96)$}

The above figure says that majority of the participants mother belonged to $31-40$ age group $63(65.6 \%)$ while 19 $(19.8 \%)$ between $21-30$ years age group and $14(14.6 \%)$ had maternal age above 40 years. Mean maternal age was 34.9 years with standard deviation of 5.4 years. The youngest age of subject mother was 23 years while the oldest was 49 years.

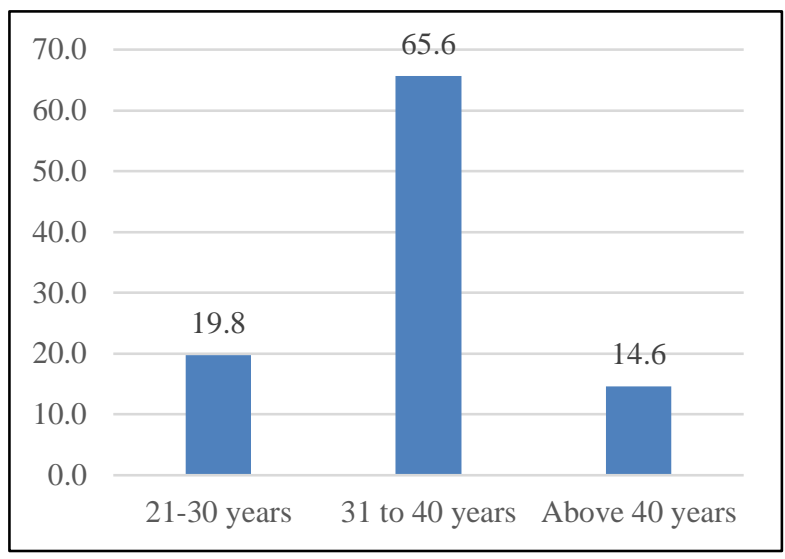

Figure 1: Distribution of study subjects according to maternal age.

\section{Figure $3(N=96)$}

Amongst the 96 study subject's majority 65 (67.7\%) were Primigravida case whereas $31(32.7 \%)$ cases were multigravida.

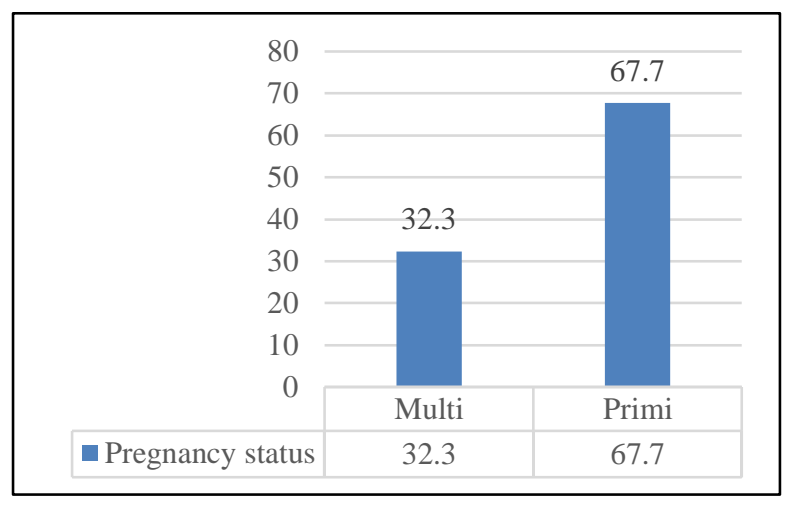

Figure 2: Distribution of study subjects according to gravida status.

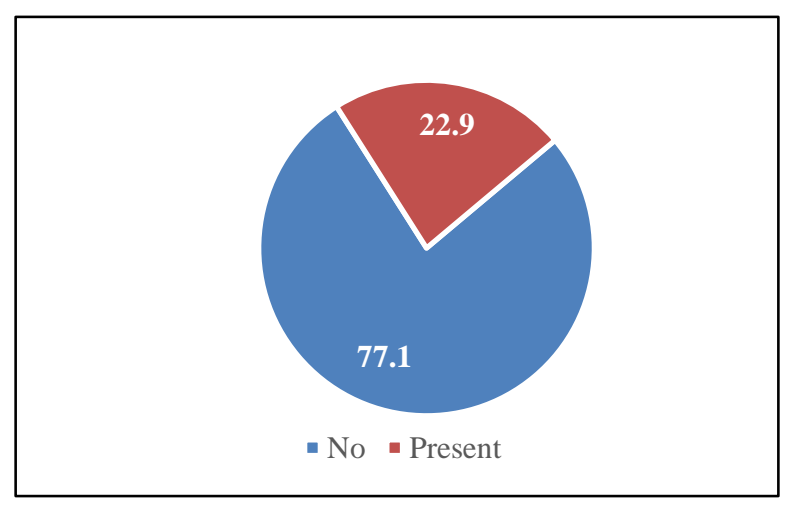

Figure 3: Distribution of study subjects according to history of abortions. 


\section{Figure $4(N=96)$}

In this study, it is observed that out of 96 study participants $22(22.9 \%)$ had a history of abortion during their previous pregnancies.

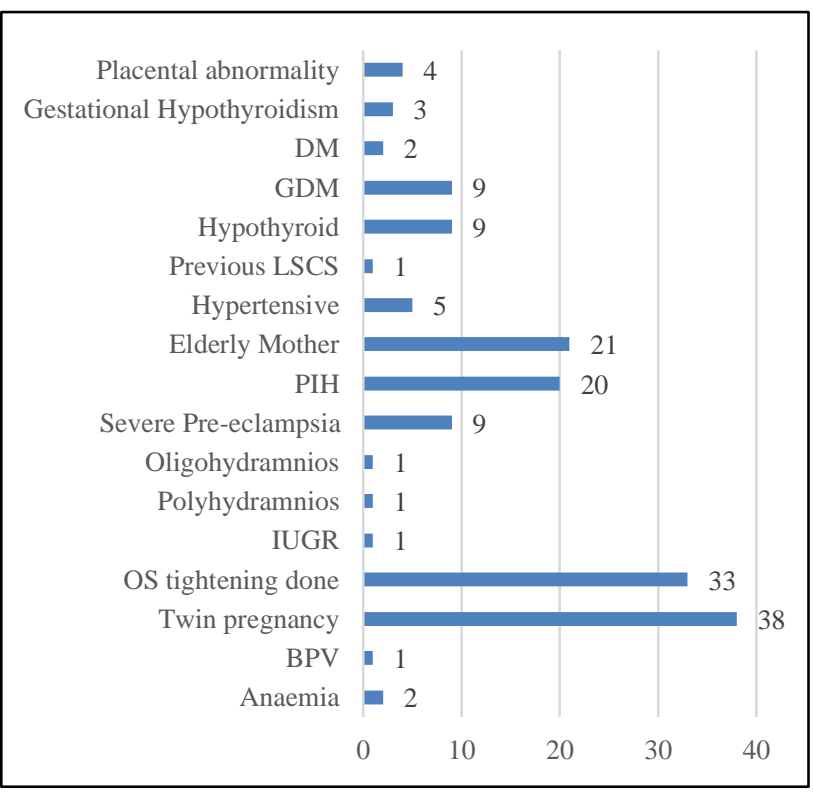

Figure 4: Distribution of study subjects according to antenatal high-risk factors among participants ( $\mathbf{N = 9 6 ) . ~}$

Figure 5 shows that the major ANC risk factors observed among the study participants were, twin pregnancy 38 $(23.7 \%)$ OS tightening done in $33(20.62 \%)$, PIH in 20 $(12.5 \%)$, elderly mother $21(13.12 \%)$, hypothyroidism, severe pre-eclampsia and GDM $(5.62 \%$ each respectively).

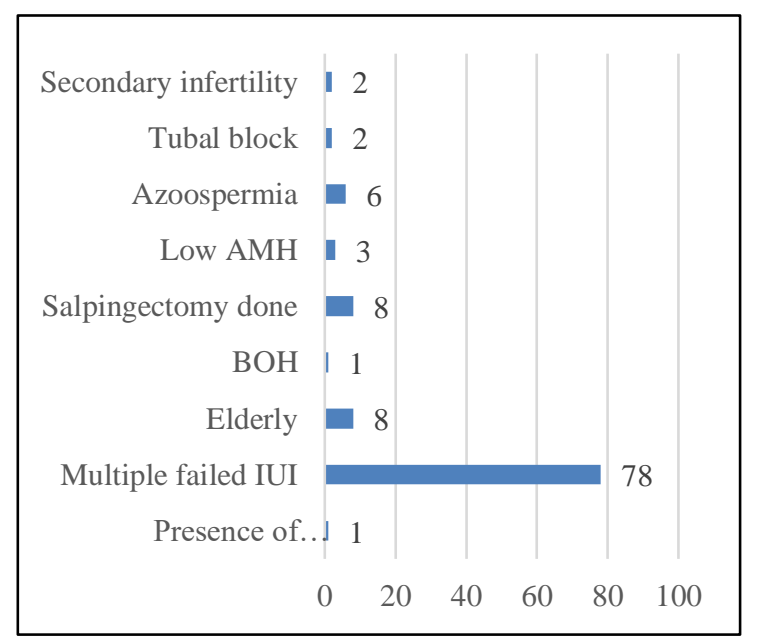

Figure 5: Distribution of subjects according to reasons for opting for IVF among participant.

A total 5 subjects were hypertensive, 4 had placental abnormality, 3 had gestational hypothyroidism, 2 had anaemia, 2 had diabetes mellitus. One each had IUGR, polyhydramnios, oligohydramnios, previous LSCS and BPV respectively.

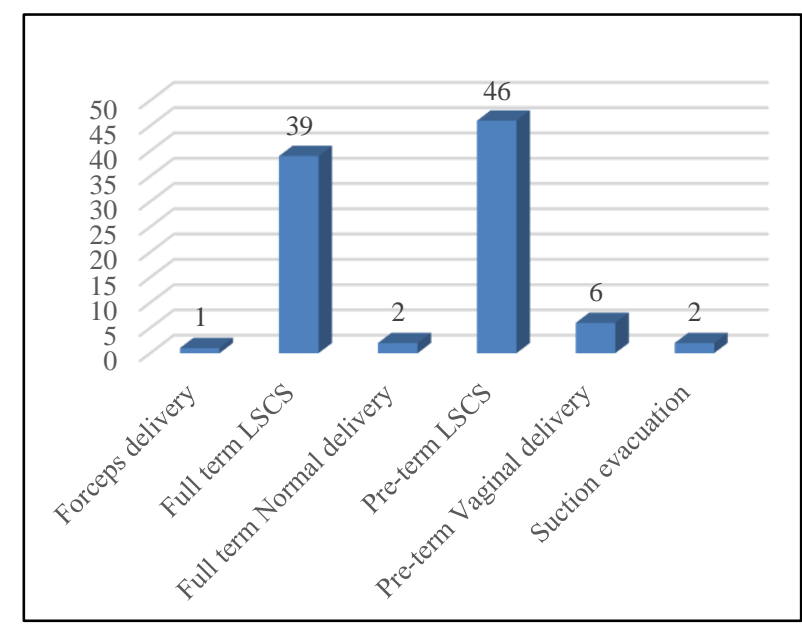

Figure 6: Distribution of study subjects according to perinatal outcome among study participants.

From the Figure 6 it is observed that the major reasons for opting IVF among study participants were, multiple failed IUI (71.6\%), advanced age (7.3\%), salpingectomy operation done (7.3\%) and Azoospermia in husband (5.5\%). Tubal block reason in 2 subjects and secondary infertility was reason in 2 subjects. $\mathrm{BOH}$ and presence of endometriosis was reason in 1 subject respectively.

From the Figure 7 it is observed that majority of the participants had to undergo pre-term LSCS 46 (47.9\%) followed by those who underwent full-term LSCS 39 $(40.6 \%)$ overall LSCS was performed in $88.5 \%$ cases. Preterm vaginal delivery in $6(6.3 \%)$, full term normal delivery and suction evacuation in 2 each and forceps delivery in 1 study participant.

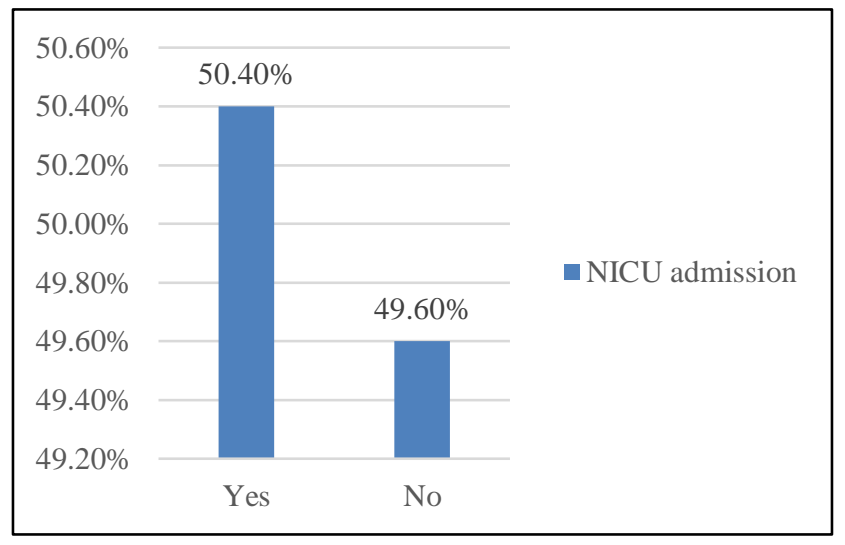

Figure 7: Distribution of study subjects according to requirement of NICU admission among babies of study participants.

From the Figure 8 it is observed that amongst 135 babies delivered, NICU admission was required in 68(50.4\%) babies. 
Table 1: Distribution of study subjects according to relation between birth weight and number of fetuses born $(\mathrm{N}=96)$.

\begin{tabular}{|llll|}
\hline Birth weight & No. of fetuses & Twins & Triplets \\
\hline Extremely low & Singleton & $7(18.4 \%)$ & $2(100 \%)$ \\
\hline Very low & $4(7.1 \%)$ & $3(7.9 \%)$ & 0 \\
\hline Low & $11(19.6 \%)$ & $15(39.5 \%)$ & 0 \\
\hline Normal & $17(30.4 \%)$ & $13(34.2 \%)$ & 0 \\
\hline Total & $24(42.9 \%)$ & $38(100 \%)$ & $2(100 \%)$ \\
\hline
\end{tabular}

Table 2: Distribution of study subjects according to relation between Preterm delivery and number of fetuses born $(\mathrm{N}=96)$.

\begin{tabular}{|lll|l|}
\hline No. of fetuses & Preterm delivery & & Chi-square, p-value \\
\hline Singleton Pregnancies & Yes & No & \\
\hline Multiple gestations & $20(35.7 \%)$ & $36(64.3)$ & 23.0313, P <0.001, HS \\
\hline
\end{tabular}

From the Table 1 it is observed that the prevalence of normal birth weight babies is more in singleton pregnancy $(42.9 \%)$ than in twin pregnancy (34. 2\%). All triplets born were extremely low birth weight.

From the Table 2, it is observed that $35.7 \%$ of singleton pregnancies delivered preterm as compared to $85 \%$ multiple pregnancies. The difference is found to be highly statistically significant with Chi-square value 23.0313 and $\mathrm{p}<0.001$.

\section{DISCUSSION}

The present observational study was conducted to study antenatal, intranatal and postnatal outcomes of In vitro fertilization at tertiary care center.

From Figure 1 it observed that $65.6 \%$ had maternal age between 31 to 40 years while $19.8 \%$ had maternal age between 21 to 30 years and mean maternal age was 34.9 years with standard deviation of 5.4 years. ${ }^{4}$

In a study conducted by Wenhao et al on perinatal and neonatal outcomes of 494 babies delivered from 972 vitrified embryo transfers found that the mean maternal age was 29.94 with standard deviation 4.08 years.

In a study conducted by Nouri et al study titled 'Obstetric and perinatal outcomes in IVF versus ICSI-conceived pregnancies at a tertiary care centre - a pilot study' mean age of mother in IVF group was 33.71 with standard deviation 4.92 years. ${ }^{5}$ Findings in our study is similar with both above study.

From Figure 2 it is observed that $67.7 \%$ were primigravida.
In a study conducted by Maman et al titled 'Obstetric outcome of singleton pregnancies conceived by in vitro fertilization and ovulation induction compared with those conceived spontaneously' observed that 169 singleton pregnancies achieved by IVF observed that 60.4 were primigravida. The findings of present study regarding percentage of primigravida were more than study by Maman et al. ${ }^{6}$

From Figure 4 it is observed that $22.9 \%$ mothers had history abortion during their previous pregnancies.

Study also showed that in 7 study participants ectopic pregnancy was observed.

In a seven year retrospective study conducted by Mustafa et al on Live birth rates are satisfactory following multiple IVF treatment cycles in poor prognosis patients in PIVET Medical Centre, Perth, Western Australia, 850 mother become pregnant after IVF of which 17 mothers had ectopic pregnancy. ${ }^{7}$

Finding of this study were not similar with our study due different in methodology.

From Figure 5 it is observed that most common ANC risk factor was twin pregnancy $(23.75 \%)$, OS lightening done $(20.62 \%)$, PIH in $12.5 \%, 5.62 \%$ were had severe preeclampsia, GDM and hypothyroid each respectively and placental abnormality in $2.5 \%$ study participants.

In a study conducted by Reubinoff et al titled 'Is the obstetric outcome of in vitro fertilized singleton gestations different from natural ones? a controlled study' in Ein-Karem, Hadassah University Hospital, Jerusalem, Israel. The obstetric outcomes of 260 consecutive singleton pregnancies achieved at the Hadassah Medical Center in Jerusalem from 1983 to 1993 were compared 
with the outcomes of 260 control spontaneous gestations matched for maternal ethnic origin, age, parity, and location and date of delivery found that PIH was complication in $11.2 \%$ pregnancies. $^{8}$

Finding of our study similar to above study in term PIH as an obstetrics complication. ${ }^{9}$

In a study conducted by Asbagh et al on fetal and maternal effects of pregnancy after using IVF / ICSI in women comprehensive Hospital in Tehran in 5 years found that $25 \%$ of all IVF/ICSI pregnancy observed that GDM was obstetrics complication in $6 \%$ study participants, pre-eclampsia in $2 \%$, placenta previa in $4 \%$ and placental abruption in $2 \%$. Finding our study similar to above mentioned study in terms of Gestational diabetes mellitus as an obstetric-complications.

From Figure 5 it is evident that in $71.6 \%$ study subject's reason for opting IVF was Multiple IUI, Endometriosis in $0.9 \%$ subjects and tubal block in $1.8 \%$ study subjects.

While in a study conducted by Asbagh et al on fetal and maternal effects of pregnancy after using IVF / ICSI in women comprehensive Hospital in Tehran observed that most common cause for opting IVF/ICSI was Male factor in $42 \%$, tubal factor in $10 \%$ and endometriosis in $10 \%$. Findings of our study not similar with above mentioned study due to difference in sociodemographic profile of study subjects.

In a study done by Perri et al titled 'Are Singleton Assisted Reproductive Technology Pregnancies at Risk of Prematurity?', It was found that within the ART group, the indications for IVF or ICSI included tubal sterility (14\%), endometriosis (5\%), male-factor infertility $(39 \%$; $19 \%$ with severe male factor, i.e., <5 million motile sperm in the ejaculate), unexplained infertility (28\%), polycystic ovary syndrome $(8 \%)$, and other female disorders $(6 \%) .{ }^{10}$ Findings of our study not similar with above mentioned study due to difference in methodology of study.

In Figure 6 it is observed that $47.9 \%$ participants were delivered Pre-term LSCS and $40.6 \%$ were full term LSCS.

In a study conducted by Smithers et al titled 'High frequency of caesarean section, antepartum haemorrhage, placenta previa, and preterm delivery in in vitro fertilization twin pregnancies' observed that elective caesarean section was done in $41 \%$ and emergency LSCS was done in $23 \%$ IVF study subjects. ${ }^{11}$ Finding of our study not similar with finding of above-mentioned study, this may be due to different in methodology and type of study.

In a study conducted by Asbagh et al on fetal and maternal effects of pregnancy after using IVF / ICSI in women comprehensive Hospital in Tehran observed that caesarean section was done in $98 \%$ study subjects. Findings of above-mentioned study is similar to current study.

From Figure 8 it is observed that $91.1 \%$ cried immediately after birth and $50.4 \%$ children required NICU admission. ${ }^{12}$

In a study conducted by Moise et al on outcome of twin pregnancies after IVF found that $40 \%$ children conceived through IVF required NICU admission. Finding our study not matched with above mentioned study.

In this study it is observed that $13.4 \%$ were neonatal death in study. In a study conducted by Fujii et al on perinatal risk in singleton pregnancies after in vitro fertilization found that in the IVF group, 23 (1.6\%) pregnancies ended with perinatal

Death compared with $596(1.1 \%)$ in the control group. ${ }^{13}$ Findings our study did not match with above mentioned study due to difference in methodology of study. This difference in the findings of the two studies may be due to the difference in type of study, the present study was centre based study while above mentioned study was registry-based study.

As per the study intrauterine foetal death occurred in $3.10 \%$ study participants.

It is also observed that $58.3 \%$ pregnancies were singleton while $39.6 \%$ were twins and $2.1 \%$ triplets. In a study Tallo et al on maternal and neonatal morbidity associated with in vitro fertilization found that of 101 IVF pregnancies $61.38 \%$ were singleton, $35.64 \%$ were twins and $2.97 \%$ were triplets. ${ }^{14}$ Findings of our study closely similar with findings of above-mentioned study.

In a study by Westergaard et al which reports data from the Danish in-vitro fertilization (IVF) registry from 1994 to 1995 including data on treatments and the results of these (perinatal outcome, cytogenetic findings and foetal malformations) in comparison with a control group matched for maternal age, parity, multiplicity and year of birth found that there were 1756 deliveries of which $24.3 \%$ twins and $1.8 \%$ triplets .Finding of our study not similar with above mentioned study as difference in methodology of both studies.

As per study it is observed that $54.1 \%$ children born were male and $45.2 \%$ were female. In a study conducted by Fujii et al on perinatal risk in singleton pregnancies after in vitro fertilization found that $50.8 \%$ were male and $49.2 \%$ female. ${ }^{16}$ Findings of our study closely similar with finding of above study.

As per Table 1 it is observed that mean weight of newborn children was $1.8 \mathrm{~kg}$ with Standard deviation $0.86 \mathrm{~kg}$. Extremely low birth weight new born were $17.8 \%$, very low birthweight $17 \%$. In a study conducted by Tallo et al 
on maternal and neonatal morbidity associated with in vitro fertilization found that IVF infant survivors had mean birth weight $2.623 \mathrm{~kg}$ with standard deviation 0.857 kg. ${ }^{17}$ Findings of our study about birth weight in IVF children is lower than above mentioned study and this may be due difference in sociodemographic profile of study participants. In a study conducted by Fujii et al on perinatal risk in singleton pregnancies after in vitro fertilization found that low birth weight among new born children was $20.6 \%$. Findings of our study about percentage of low birth weight in IVF children is more than above mentioned study and this may be due difference in sociodemographic profile of study participants. $^{18}$

In a study conducted by Chung et al titled 'factors influencing adverse perinatal outcomes in pregnancies achieved through use of in vitro fertilization' found that mean birth weight was $2.118 \mathrm{~kg}$ with standard deviation $0.605 \mathrm{~kg}$. Findings of our study about birth weight in IVF children is lower than above mentioned study and this may be due difference in sociodemographic profile of study participants. ${ }^{18}$

From study it is observed that normal birth weight was more in singleton pregnancy $(42.9 \%)$ as compared to in twin pregnancies (34.2\%), out of 38 twin pregnancy delivered extremely low birth weight percentage was $18.4 \%, 7.9 \%$ very low birth weight and $39.5 \%$ low birth, all triplets (100\%) were extremely low birth weight.

As per study it is observed that mean weight in singleton pregnancies was more as compared to twin pregnancies and there was significant association between birth weight of babies and number of foetuses $(\mathrm{p}<0.05)$.

From study it is observed that $85 \%$ multiple gestation were delivered preterm as compared to $35.7 \%$ singleton pregnancies and significant association was found between preterm delivery and number of foetuses delivered (Chi square $=22.22$ and $p$ value $=23.22$ ) suggesting that pre-term deliveries are more common in multiple gestation as compared with singleton pregnancies.

In a study conducted by Muhieddine titled 'outcome of twin, triplet, and quadruplet in vitro fertilization pregnancies: the Norfolk experience found that triplet and quadruplet IVF pregnancies have increased obstetrical and neonatal complications compared with IVF twins. ${ }^{19}$

As per Table 2 it is observed that $56.3 \%$ study participants delivered preterm.

In a case control study conducted by Tallo et al on Maternal and neonatal morbidity associated with in vitro fertilization found that percentage of preterm delivery was $37 \% .^{20}$
Finding of our study not matched with above mentioned study and this may be due to difference in methodology of study and sociodemographic factor of study participants.

In a study conducted by Kallen et al on infant outcome after different IVF fertilization method found that among the 10,088 IVF singleton births, information on gestational duration existed for 10,062. Preterm birth (less than 37 completed weeks) occurred in 964 infants (9.6\%), compared with 5.3\% among all singleton births.

Finding of our study not matched with above mentioned study and this may be due to difference in methodology of study and sociodemographic factor of study participants.

From the study it is also observed that in $28.9 \%$ twin pregnancies mother had PIH and in 50\% of triplet pregnancies mother had PIH. GDM was present $10.7 \%$ mother of singleton pregnancies and $7.9 \%$ in twin pregnancies.

\section{Limitations}

The study was undertaken in the tertiary maternity hospital in a Metropolitan City as it a single centre based study findings cannot be generalized to whole population. The present study was conducted with a relatively small sample size and hence the findings cannot be generalized.

\section{CONCLUSION}

A total $65.6 \%$ belongs to age group 31 to 40 years, $67.7 \%$ were gravida $1.22 .9 \%$ had a history of abortion during previous pregnancies and $7.3 \%$ had history of previous ectopic pregnancy. $51.4 \%$ of study subjects had history of previous hysterolaporoscopy. In $23.75 \%$ twin pregnancy was significant as an antenatal complication and $20.63 \%$ had OS tightening done. Most common reason for opting IVF was multiple failed IUI (71.6\%). 47.9\% undergo Preterm LSCS and $40.6 \%$ Full term LSCS. $91.1 \%$ of babies cried immediately after birth and $50.4 \%$ babies required NICU admission. $13.4 \%$ babies had neonatal death and $3.1 \%$ were IUFD. $58.30 \%$ pregnancies were singleton. $54.1 \%$ of total babies were male and $45.2 \%$ were female. Mean birth weight was $1.87 \mathrm{Kg}$ with standard deviation $0.86 \mathrm{~kg}$ and $72.6 \%$ children were born low birth weight. Twin pregnancies were associated with less birth weight as compared to singleton pregnancies. Statistical significance $(\mathrm{p}<0.001)$ was found in between no of foetuses delivered and preterm delivery. Preterm deliveries are more common in multiple gestation as compared to singleton. $56.3 \%$ birth were preterm birth.

PIH complication is most common in multiple gestations and GDM was observed in $10.7 \%$ of singleton pregnancies. 
Thus, here we see that though fertility has been made possible through ART, not all are benefited. The abovementioned range of outcomes is an eye-opener to combat the misconceptions held regarding IVF. It also helps the infertile couples to calculate the risk benefit ratio, and plan the procedure keeping in mind the monetary needs.

\section{ACKNOWLEDGMENTS}

Authors would like to thank Seth G.S. Medical college and KEM hospital, Nowrosjee Wadia Maternity Hospital, the IVF centre at Wadia hospital, the Department of Obstetrics and Gynaecology to conduct the study and the Department of Preventive and Social Medicine for the help in statistical analysis.

Funding: No funding sources

Conflict of interest: None declared

Ethical approval: The study was approved by the Institutional Ethics Committee

\section{REFERENCES}

1. Ginsburg ES RC. Assisted reproduction. 7th ed. Elsevier Saunders; 2014.

2. Aiken CEM, Brockelsby JC. Fetal and Maternal Consequences Of Pregnancies Conceived Using Art. Fetal Matern Med Rev. 2014;25:281-94.

3. Källén B, Finnström O, Olausson, Nygren PO. In vitro fertilization ( IVF ) in Sweden : infant outcome after different IVF fertilization methods. 2005;84.

4. Shi W, Xue X, Zhang S, Zhao W, Liu S, Ph D, et al. Perinatal and neonatal outcomes of 494 babies delivered from 972 vitri fi ed embryo transfers. Fertil Steril. 2012;97:1338-42.

5. Nouri K, Ott J, Stoegbauer L, Pietrowski D, Frantal $\mathrm{S}$, Walch K. Obstetric and perinatal outcomes in IVF versus ICSI-conceived pregnancies at a tertiary care center - a pilot study. Reprod Biol Endocrinol 2013;11:1.

6. Maman E, Lunenfeld E, Levy A, Ph D, Vardi H, Sc M. Obstetric outcome of singleton pregnancies conceived by in vitro fertilization and ovulation induction compared with those conceived spontaneously. 1998;70:2-7.

7. Mustafa, Kamarul B, Keane KN, Walz NL, Mitrovic KI, Hinchliffe PM, Yovich JL. Live birth rates are satisfactory following multiple IVF treatment cycles in poor prognosis patients. Phytochem Lett. 2016.

8. Reubinoff BE. Is the obstetric outcome of in vitro fertilized singleton gestations different from natural ones? A controlled study. 1997;02:82.

9. Akbari P. Fetal and Maternal Effects of Pregnancy after Using IVF / ICSI in Women Comprehensive Hospital in Tehran in 5 Years. Sch J Appl Med Sci. 2016;4:3577-80.

10. Perri T, Chen R, Yoeli R, Merlob P, Orvieto R, Shalev $\mathrm{Y}$, et al. Are singleton assisted reproductive technology pregnancies at risk of prematurity? J Assist Reprod Genet. 2001;18:245-9. Chen Y,
Zheng X, Yan J, Qiao J, Liu P. Neonatal outcomes after the transfer of vitrified blastocysts: closed versus open vitrification system 2013:1-5.

11. Smithers PR, Halliday J, Hale L, MacKenzie Talbot J, Breheny S, Healy D. High frequency of cesarean section, antepartum hemorrhage, placenta previa, and preterm delivery in in-vitro fertilization twin pregnancies. Fertil Steril. 2003;80:666-8.

12. Moise J, Laor A, Armon Y, Gur I, Gale R. The outcome of twin pregnancies after IVF. 1998; 13:1702-5.

13. Fujii M, Matsuoka R, Ph D, Bergel E, Ph D. Perinatal risk in singleton pregnancies after in vitro fertilization. Fertil Steril. 2010;94:2113-7.

14. Tallo CP, Vohr B, Oh W, Rubin LP, Seifer DB, Haning R V. Maternal and neonatal morbidity associated with in vitro fertilization. J Pediatr. 1995; 127:794-800.

15. Westergaard HB, Johansen AMT. Danish National In-Vitro Fertilization Registry 1994 and 1995: a controlled study of births , malformations and cytogenetic findings. 1999;14:1896-902.

16. Fujii M, Matsuoka R, Ph D, Bergel E, Ph D. Perinatal risk in singleton pregnancies after in vitro fertilization. Fertil Steril. 2010;94:2113-7.

17. Tallo CP, Vohr B, Oh W, Rubin LP, Seifer DB, Haning R V. Maternal and neonatal morbidity associated with in vitro fertilization. $\mathrm{J}$ Pediatr. 1995; 127:794-800.

18. Fujii M, Matsuoka R, $\mathrm{Ph} \mathrm{D}$, Bergel E, $\mathrm{Ph} \mathrm{D}$. Perinatal risk in singleton pregnancies after in vitro fertilization. Fertil Steril. 2010;94:2113-7.

19. D MASM, D JPTM, Ph D, N CKBS, D SJMM. Create account Sign in Outcome of twin , triplet, and quadruplet in vitro fertilization pregnancies: the Norfolk experience * 2019:1-3. [20] Poikkeus P, Gissler M, Tiitinen A. Obstetric and neonatal outcome after single embryo transfer 2007;22:10739.

20. Tallo CP, Vohr B, Oh W, Rubin LP, Seifer DB, Haning R V. Maternal and neonatal morbidity associated with in vitro fertilization. $\mathrm{J}$ Pediatr. 1995; 127:794-800.

21. Källén B, Finnström O, Olausson, Nygren KG. In vitro fertilization ( IVF ) in Sweden : infant outcome after different IVF fertilization methods 2005;84. [23]Akbari P et al. Fetal and Maternal Effects of Pregnancy after Using IVF / ICSI in Women Comprehensive Hospital in Tehran in 5 Years. Sch $\mathbf{J}$ Appl Med Sci. 2016;4:3577-80.

22. Rahu K, Allvee K, Karro H, Rahu M. Singleton pregnancies after in vitro fertilization in Estonia: A register-based study of complications and adverse outcomes in relation to the maternal sociodemographic background. BMC Pregnancy Childbirth. 2019;19:1-9.

23. Stewart LM, Holman CDAJ, Finn JC, Preen DB, Hart R. In vitro fertilization is associated with an increased risk of borderline ovarian tumours. Gynecol Oncol. 2013;129:372-6. 
24. Tough SC, Greene CA, Svenson LW, Belik J. Effects of in vitro fertilization on low birth weight, preterm delivery, and multiple birth. J Pediatr. 2000;136:618-22.

25. Gissler M, Silverio MM, Hemminki E. In-vitro fertilization pregnancies and perinatal health in Sign in Oxford Academic account Sign in via your Institution. 2019:1-7.

26. Helmerhorst FM, Perquin DAM, Donker D, Keirse MJNC. Papers Perinatal outcome of singletons and twins after assisted conception: a systematic review of controlled studies. 2004;1-5.-21.

Cite this article as: Balsarkar GD, Pol SP. Study of the obstetrics and perinatal outcome of in vitro

fertilization pregnancies at tertiary care centre. Int $\mathrm{J}$

Reprod Contracept Obstet Gynecol 2021;10:2225-33. 